\title{
The Impact of Information Technology on Library Anxiety: The Role of Computer Attitudes
}

Over the past two decades, computer-based technologies have become dominant forces to shape and reshape the products and services the academic library has to offer. The application of library technologies has had a profound impact on the way library resources are being used. Although many students continue to experience high levels of library anxiety, it is likely that the new technologies in the library have led to them experiencing other forms of negative affective states that may be, in part, a function of their attitude towards computers. This study investigates whether students' computer attitudes predict levels of library anxiety.

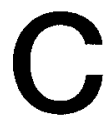
omputers and information technologies have experienced considerable growth over the past two decades. As such, familiarity with computers is rapidly becoming a basic skill and a prerequisite for many tasks. Although not every college student is equally prepared for the rising demand of computer skills in the information age, computer literacy is increasingly becoming a gatekeeper for students' academic success. ${ }^{1}$ Gaps in computer literacy and skills can leave many students behind not only in their academic achievement but also in their future job-market success.

The unprecedented pace of technological change in the development of digital information networks and electronic services in recent years has helped to expand the role of the academic library. Once only a storehouse of printed materials, it is now a technology-laden information network where students can conduct research in a mixed print and digital-resource environment, experience the use of advanced information technologies, and hone their computer skills.

Yet, many students are struggling to cope with the changes brought on by the rapid advances of information technologies. Academic libraries of various sizes have spent a large percentage of their material budget on electronic commercial content, and the trend will continue. ${ }^{2}$ These days, college students are faced with the choices of ever-changing modes of electronic accessing tools, interfaces, and protocols along with the traditional print resources in the library. The fact that the same journal article may be available in multiple vendors' aggregator

Qun G. Jiao (gerry_jiao@baruch.cuny.edu) is Reference Librarian and Associate Professor at Newman Library, Baruch College, City University of New York, and Anthony J. Onwuegbuzie (Tony Onwuegbuzie@aol.com) is Associate Professor at the College of Education, University of South Florida, Tampa. sites (such as EBSCOhost and Gale Group) makes the navigation through these bibliographic databases more complex and challenging. Relevant sources must be identified and navigation protocols must be learned before appropriate information and contents can be found. Furthermore, having located a citation, students still have to search the library online catalog to find out if the journal or book is available in the library and, if not, know how to make an interlibrary loan request either on paper or electronically. ${ }^{3}$ Anxiety levels can be high and patience levels can be low at varying times of conducting library research. ${ }^{4}$

That students experience various levels of apprehension when using academic libraries is not a new phenomenon. Indeed, the phenomenon is prevalent among college students in the United States and many other countries, and is widely known as library anxiety. Mellon first coined the term in her study in which she noted that 75 percent to 85 percent of undergraduate students described their initial library experiences in terms of anxiety. According to Mellon, feelings of anxiety stem from either the relative size of the library; a lack of knowledge about the location of materials, equipment, and resources of the library; how to initiate library research; or how to proceed with a library search. ${ }^{6}$ Library anxiety is an unpleasant feeling or emotional state with physiological and behavioral concomitants that come to the fore in library settings. Typically, library-anxious students experience negative emotions, including ruminations, tension, fear, and mental disorganization, which prevent them from using the library effectively." A student who experiences library anxiety usually undergoes either emotional or physical discomfort when faced with any library or library-related task. ${ }^{8}$ Library anxiety may arise from a lack of self-confidence in conducting research, lack of prior exposure to academic libraries, the inability to see the relevance of libraries to one's field of interest, and lack of familiarity with library equipment and technologies. Library anxiety is often accorded special attention because of its debilitating effects on students' academic achievement.?

Although many students continue to experience high levels of library anxiety, it is likely that the new technologies and electronic databases in libraries have led to students experiencing other forms of negative affective states. In particular, it is likely that library anxiety experienced by students is, in part, a function of their attitudes toward computers. Consistent with this assertion, Mizrachi and Shoham and Mizrachi reported a statistically significant relationship between library anxiety and computer attitudes. ${ }^{10}$ They noted in their research that home and work usage of computers, computer games, word processors, computer spreadsheets, and the Internet are all related to the dimensions of library anxiety found among Israeli students to varying degrees. 
Similarly, Jerabek, Meyer, and Kordinak found levels of computer anxiety to be related to levels of library anxiety for both men and women. ${ }^{11}$ These studies focused exclusively on undergraduate students. However, no study has examined this relationship among graduate students, a population that uses the academic library more than any other student population.

Over the past fifteen years, a large body of research literature on computer attitudes has been generated. In particular, many researchers have studied the relationship between computer attitudes and computer use. ${ }^{12}$ The importance of beliefs and attitudes towards computers and technologies is widely acknowledged. ${ }^{13}$ Students' computer attitudes arguably impact their willingness to engage in computer-related activities in colleges and universities where effectively using library electronic resources represents an increasingly important part of college education. Negative computer attitudes may inhibit students' interests in learning to use the library resources and thereby weaken their academic performance levels, while at the same time elevating levels of library anxiety. McInerney, McInerney, and Sinclair observed that negative perceptions about computers among student teachers may accompany feelings of anxiety, including worries about being embarrassed, looking foolish, and even damaging the computer equipment. ${ }^{14}$ Further, there is often a negative relationship between prior experience with computers and computer anxiety experienced by individuals. ${ }^{15}$

Until recently, library anxiety has only been interpreted in the context of the library setting-that is, a phenomenon that occurs while students are undertaking library tasks. Jiao, Onwuegbuzie, and Lichtenstein defined library anxiety as "an uncomfortable feeling or emotional disposition, experienced in a library setting, which has cognitive, affective, physiological, and behavioral ramifications." ${ }^{16}$ At the same time, unprecedented technological advancement has had a profound impact on the products and services offered by academic libraries. Students now are able to conduct sophisticated library searches from the comfort of their homes. It is clear that the construct of library anxiety needs to be expanded in the new library and information environment, incorporating into its definition other variables that are relevant for the changing library and information context. Because many library users spend a significant portion of their time using computer-based technologies to conduct information searches, it is natural to ask, to what extent does library anxiety stem from students' prior attitudes and experiences with computers and library technologies? However, with the exception of the studies conducted by Mizrachi and Shoham and Mizrachi on Israeli undergraduate students, this link has not been examined. ${ }^{17}$ Thus, the present study investigated the relationship between computer attitudes and library anxiety in the rapidly changing library and information environment. As such, the current inquiry replicated the works of Mizrachi, Shoham and Mizrachi, and Jerabek, Meyer, and Kordinak by examining the degree to which computer attitudes predict levels of library anxiety among graduate students in the United States. ${ }^{18}$ It was expected that findings from this study would help to increase the understanding of the construct of library anxiety. Indeed, research in this area has become critical in higher education where educators are responsible for graduating students with the skills necessary to thrive and to lead in a rapidly changing technological environment in the twenty-first century.

\section{Method}

\section{Participants}

Participants were ninety-four African American graduate students enrolled in the College of Education at a historically Black college and university in the eastern U.S. All participants were solicited in either a statistics or a measurement course at the time that the investigation took place. In order to participate in the study, students were required to sign an informed-consent document that was given during the first class session of the semester. The majority of the participants were female. Ages of the participants ranged from twenty-two to sixty-two years $($ Mean $=30.40, \mathrm{SD}=8.75)$.

\section{Instruments and Procedure}

All participants were administered two scales, namely, the Computer Attitude Scale (CAS) and the Library Anxiety Scale (LAS). The CAS, developed by Loyd and Gressard, contains forty Likert-type items that assess individuals' attitudes toward computers and the use of computers. ${ }^{19}$ This instrument consists of the following four scales, which can be used separately: (1) anxiety or fear of computers; (2) confidence in the ability to use computers; (3) liking or enjoying working with computers; and (4) computer usefulness. Loyd and Gressard reported coefficient alpha reliability coefficients of $.86, .91, .91$, and .95 for scores pertaining to computer anxiety, computer confidence, computer liking, and total scales, respectively. For the present study, the score reliabilities were as follows:

- computer anxiety, 84 (95 percent confidence interval $\mathrm{CI}=.79, .88$ );

- computer confidence, .81 (95 percent $\mathrm{CI}=.75, .86$ );

- computer liking, 89 (95 percent $\mathrm{CI}=.85, .92$ ); and

- computer usefulness, .76 (95 percent $\mathrm{CI}=.68, .83$ ). 
The LAS, developed by Bostick, contains forty-three 5-point Likert-format items that assess levels of library anxiety experienced by college students. ${ }^{20}$ It also contains the following five subscales:

1. barriers with staff;

2. affective barriers;

3. comfort with the library;

4. knowledge of the library; and

5. mechanical barriers.

A high score on any subscale represents high levels of anxiety in that area. Jiao and Onwuegbuzie, in their examination of the score reliability reported on LAS in the extant literature, found that it has typically been in the adequate to high range for the subscale and total-scale scores. ${ }^{21}$ Based on their analysis, Onwuegbuzie, Jiao, and Bostick concluded that "not only does the [LAS] produce scores that yield extremely reliable estimates, but also these estimates are remarkably consistent across samples with different cultures, nationalities, ages, years of study, gender composition, educational majors, and so forth."'22 For the current investigation, the subscales generated scores for the combined sample that had a classical theory alpha reliability coefficient of .89 (95 percent $\mathrm{CI}=.85, .92)$ for barriers with staff, .84 (95 percent $\mathrm{CI}=.79, .88$ ) for affective barriers, .53 (95 percent $\mathrm{Cl}=.37, .66)$ for comfort with the library, .62 $(95$ percent $\mathrm{CI}=.48 .73$ ) for knowledge of the library, and .70 (95 percent $\mathrm{CI}=.58, .79$ ) for mechanical barriers.

\section{Analysis}

A canonical correlation analysis was conducted to identify a combination of library anxiety dimensions (barriers with staff, affective barriers, comfort with the library, knowledge of the library, and mechanical barriers) that might be simultaneously related to a combination of computer-attitude dimensions (computer anxiety, computer liking, computer confidence, and computer usefulness). Canonical correlation analysis is used to examine the relationship between two sets of variables whereby each set contains more than one variable..$^{23}$ In the present investigation, the five dimensions of library anxiety were treated as the dependent multivariate set of variables, and the four dimensions of computer attitudes formed the independent multivariate profile. The number of canonical functions (factors) that can be produced for a given dataset is equal to the number of variables in the smaller of the two variable sets. Because the library-anxiety set contained five dimensions and the computer-attitude set contained four variables, four canonical functions were generated.

For any significant canonical coefficient, the standardized canonical-function coefficients and structure coefficients were then interpreted. Standardized canonicalfunction coefficients are computed weights that are applied to each variable in a given set in order to obtain the composite variate used in the canonical correlation analysis. As such, standardized canonical-function coefficients are equivalent to factor-pattern coefficients in factor analysis or to beta coefficients in a regression analysis. ${ }^{24}$ Conversely, structure coefficients represent the correlations between a given variable and the scores on the canonical composite (latent variable) in the set to which the variable belongs. ${ }^{25}$ Thus, structure coefficients indicate the degree to which each variable is related to the canonical composite for the variable set. Indeed, structure coefficients are essentially bivariate correlation coefficients that range in value between -1.0 and +1.0 inclusive. ${ }^{26}$ The square of the structure coefficient yields the proportion of variance that the original variable shares linearly with the canonical variate.

\section{Results}

Table 1 presents the intercorrelations among the five dimensions of library anxiety and the four dimensions of computer attitude. Of particular interest were the twenty correlations between the library-anxiety subscale scores and the computer-attitude subscale scores. It can be seen that, after applying the Bonferroni adjustment, four of these relationships were statistically significant. Specifically, computer liking was statistically significantly related to affective barriers, knowledge of the library, and comfort with the library. Using Cohen's criteria of .1, .3, and .5 for small, medium, and large relationships, respectively, the first two relationships (involving affective barriers and knowledge of the library) were medium, and the third relationship (between computer liking and comfort with the library) was large. ${ }^{27}$ In addition to these three relationships, the association between computer usefulness and knowledge of the library also was statistically significant, with a medium effect size.

The correlation matrix in table 1 was used to examine the multivariate relationship between library anxiety and computer attitudes. This relationship was assessed via a canonical correlation analysis. The canonical analysis revealed that the four canonical correlations combined were statistically significant $(p<.0001)$. Also, when the first canonical root was removed, the remaining three canonical roots were not statistically significant. In fact, removal of subsequent canonical roots did not lead to statistical significance. Together, these results suggested that only the first canonical function was statistically significant, but the remaining three roots were not statistically significant. This first canonical root also was practically significant $\left(R_{c 1}=.63\right)$, contributing 40.8 percent $\left(R_{\mathrm{Cl}}{ }^{2}\right)$ to the shared variance, which represents a large effect size. ${ }^{28}$ 
Data pertaining to the first canonical root are presented in table 2, which provides both standardized function coefficients and structure coefficients. Using a cutoff correlation of 0.3 , the standardized canonical-function coefficients revealed that affective barriers, comfort with the library, and knowledge of the library made important contributions to the library-anxiety set, with affective barriers and comfort with the library making similarly large contributions. ${ }^{29}$ With regard to the computer-attitude set, computer anxiety, computer liking, and computer confidence made noteworthy contributions, with the latter two dimensions making the most noteworthy contributions. The structure coefficients revealed that all five dimensions of library anxiety made important contributions to the first canonical variate. The square of the structure coefficient indicated that barriers with staff, affective barriers, comfort with the library, and knowledge of the library made similarly large contributions, explaining 67.2 percent, 72.3 percent, 72.3 percent, and 60.8 percent of the variance, respectively. With regard to the computerattitude set, computer liking and computer usefulness made important contributions. These variables explained 64.0 percent and 16.8 percent of the variance, respectively.

Comparing the standardized and structure coefficients indicated that computer anxiety and computer confidence served as suppressor variables because the standardized coefficients associated with these variables were large, whereas the corresponding structure coefficients were relatively small..$^{30}$ Suppressor variables are variables that assist in the prediction of dependent variables due to their correlation with other independent variables. ${ }^{31}$ Thus, the inclusion of computer anxiety and computer confidence in the canonical correlation model strengthened the multivariate relationship between library anxiety and computer attitudes.

\section{Discussion}

The purpose of this study was to investigate the relationship between computer attitudes and library anxiety among African American graduate students. Specifically, the multivariate link between these two constructs was examined. A canonical correlation analysis revealed a strong multivariate relationship between library anxiety and computer attitudes. The library-anxiety subscale scores and computer-attitudes subscale scores shared 40.82 percent of the common variance. Specifically, computer liking and computer usefulness were related simultaneously to the following five dimensions of library anxiety: barriers with staff, affective barriers, comfort with the library, knowledge of the library, and mechanical barriers. Computer anxiety and computer confidence served as suppressor vari- ables. Thus, computer attitudes predict levels of library anxiety.

As such, the present findings are consistent with those of Mizrachi and Shoham and Mizrachi, who found a statistically significant relationship between computer attitudes and the following seven dimensions of the Hebrew Library-Anxiety Scale, a modified version of LAS developed by the authors for their Israeli sample:

1. Staff

2. Knowledge

3. Language

4. Physical Comfort

5. Library Computer Comfort

6. Library Policies and Hours, and

7. Resources. ${ }^{32}$

According to its authors, the Staff factor refers to students' attitudes towards librarians and library staff and their perceived accessibility. The Knowledge factor pertains to how students rate their own library expertise. The Language factor relates the extent to which using Englishlanguage searches and materials yield discomfort. Physical Comfort evaluates how much the physical facility negatively affects students' satisfaction and comfort with the library. Library Computer Comfort assesses the perceived trustworthiness of library computer facilities and the quality of directions for using them. Library Policies and Hours concerns students' attitudes toward library rules, regulations, and hours of operation. Finally, Resources refers to the perceived availability of the desired material in the library collection. The correlations between the dimensions of library anxiety and computer attitudes ranged from .11 (physical comfort) to .47 (knowledge). The current results also replicate those of Jerabek, Meyer, and Kordinak, who found levels of computer anxiety to be related to levels of library anxiety for both men and women. ${ }^{33}$

Nevertheless, caution should be exercised in generalizing the current findings to all graduate students. Though the present study examined the association between library anxiety and computer attitudes among African American graduate students, it should not be assumed that this relationship would hold for other racial groups. Jiao, Onwuegbuzie, and Bostick found that African American students attending a research-intensive institution reported statistically significantly lower levels of library anxiety associated with barriers with staff, affective barriers, and comfort with the library than did Caucasian American graduate students enrolled at a doctoral-granting institution, with effect sizes ranging from moderate to large. ${ }^{34}$ In a follow-up study, Jiao and Onwuegbuzie compared African American and Caucasian American students with respect to library anxiety, controlling for educational background by selecting both racial groups from the same institution. ${ }^{35}$ No statistically significant racial differences 
Table 1. Intercorrelations among the Library-Anxiety Subscales and Computer-Attitude Subscales

\begin{tabular}{|c|c|c|c|c|c|c|c|c|}
\hline Subscale & 2 & 3 & 4 & 5 & 6 & 7 & 8 & 9 \\
\hline 2. Affective Barriers & & $.56^{\star}$ & $.52^{*}$ & $.40^{*}$ & -.05 & .02 & $-.37^{*}$ & -.23 \\
\hline 4. Knowledge of the Library & & & & $.39^{*}$ & -.21 & -.11 & $-.37^{*}$ & -.32 \\
\hline 6. Computer Anxiety & & & & & & $.77^{*}$ & $.48^{*}$ & $.46^{\prime}$ \\
\hline 7. Computer Confidence & & & & & & & $.67^{\star}$ & .36 \\
\hline 8. Computer Liking & & & & & & & & $.43^{\prime}$ \\
\hline 9. Computer Usefulness & & & & & & & & \\
\hline
\end{tabular}

*Indicates a statistically significant relationship after the Bonferroni adjustment.

Table 2. Canonical Solution for Third Function-Relationship between Library-Anxiety Subscales and Computer-Attitude Subscales

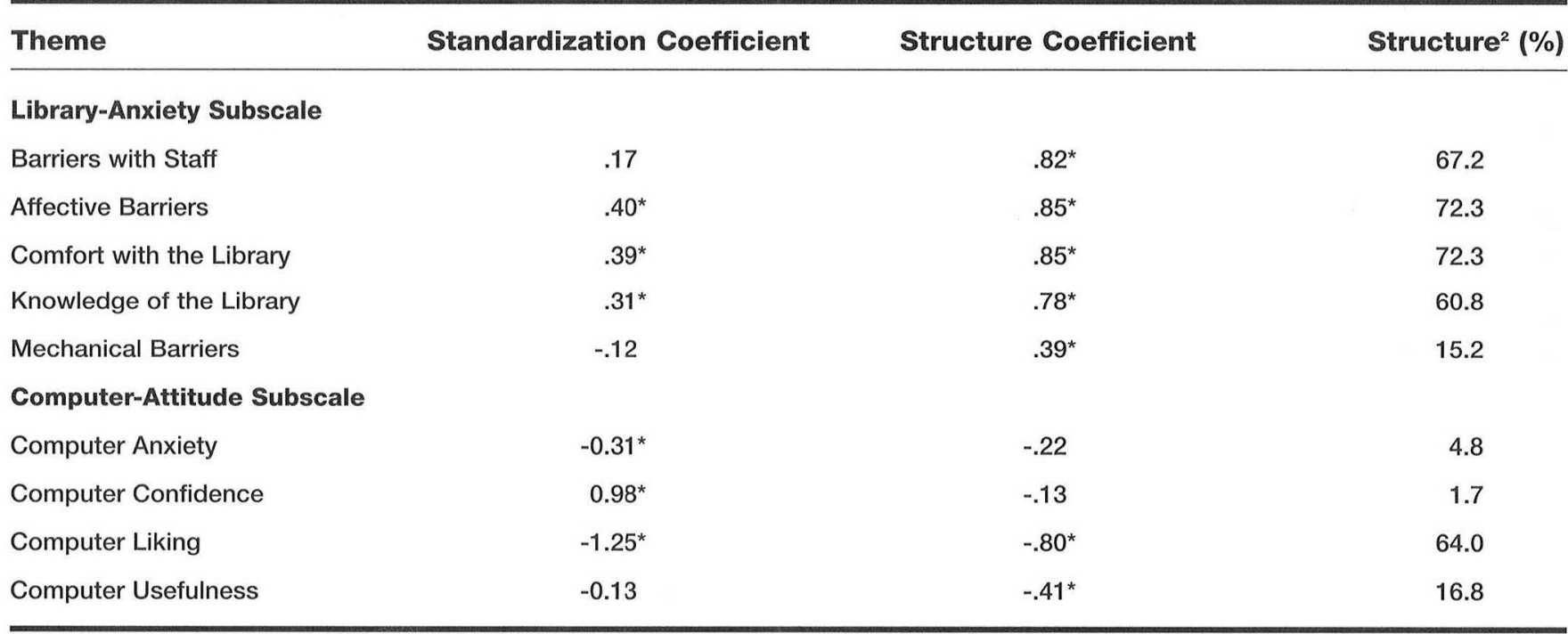

*Loadings with the effect sizes larger than .3.

were found in library anxiety for any of the five dimensions of LAS. However, across all five library-anxiety measures, the African American sample reported lower scores than did the Caucasian American sample. In fact, using the test of trend by Onwuegbuzie and Levin, they found that the consistency with which the African American graduate students had lower levels of library anxiety than did the Caucasian American students was both statistically and practically significant. ${ }^{36}$ Thus, Jiao and Onwuegbuzie's results, alongside those of Jiao, Onwuegbuzie, and Bostick, suggest that racial differences in library anxiety prevail. ${ }^{37}$ Thus, future research should investigate whether the relationship between library anxi- ety and computer attitudes found in the present study among African American graduate students also exists among Caucasian American graduate students, as well as among other racial groups.

Further, the causal direction of the relationship found in the current study should be investigated. That is, future studies should investigate whether library anxiety places a person more at risk for experiencing poor computer attitudes, or whether the converse is true. More research also is needed to determine how computer attitudes might play a role in the library context.

Notwithstanding, it appears that the construct of library anxiety can be expanded to include the construct 
of computer attitudes. Indeed, one implication of the findings is that Bostick's LAS should be modified to include dimensions of computer attitudes. ${ }^{38}$ Such a modification likely would facilitate the identification of library-anxious students. By identifying students with high levels of library anxiety and poor computer attitudes, library educators and others could help them improve their dispositions and provide them with the skills necessary to negotiate the rapidly changing technological environment, thereby putting them in a better position to be lifelong learners.

\section{References}

1. Susan M. Piotrowski, Computer Training: Pathway from Extinction (ERIC Document Reproduction Service, ED 348955 , 1992).

2. Thomas H. Hogan, "Drexel University Moves Aggressively from Print to Electronic Access for Journals (Interview with Carol Hansen Montgomery, Dean of Libraries)," Computers in Libraries 21, no. 5 (May 2001): 22-27.

3. M. Claire Stewart and H. Frank Cervone, "Building a New Infrastructure for Digital Media: Northwestern University Library," Information Technology and Libraries 22, no. 2 (June 2003): 69-74.

4. Carol C. Kuhlthau, "Longitudinal Case Studies of the Information Search Process of Users in Libraries," Library and Information Science Research 10 (July 1988): 257-304; Carol C. Kuhlthau, "Inside the Search Process: Information Seeking from the User's Perspective," Iournal of the American Society for Information Science 42, no. 5 (June 1991): 361-71; Carol C. Kuhlthau, Seeking Meaning: A Process Approach to Library and Information Services (Norwood, N.J.: Ablex, 1993); Carol C. Kuhlthau, "Students and the Information Search Process: Zones of Intervention for Librarians," Advances in Librarianship 18 (1994): 57-72; Carol C. Kuhlthau et al., "Validating a Model of the Search Process: A Comparison of Academic, Public, and School Library Users," Library and Information Science Research 12, no. 1 (Jan.-Mar. 1990): 5-31.

5. Constance A. Mellon, "Library Anxiety: A Grounded Theory and Its Development," College \& Research Libraries 47, no. 2 (Mar. 1986): 160-65.

6. Ibid.

7. Qun G. Jiao, Anthony J. Onwuegbuzie, and Art Lichtenstein, "Library Anxiety: Characteristics of 'At-Risk' College Students," Library and Information Science Research 18 (spring 1996): 151-63.

8. Constance A. Mellon, "Attitudes: The Forgotten Dimension in Library Instruction," Library Journal 113 (Sept. 1, 1988): 137-39; Constance A. Mellon, "Library Anxiety and the NonTraditional Student," in Reaching and Teaching Diverse Library User Groups, ed. Teresa B. Mensching (Ann Arbor, Mich.: Pierian, 1989), 77-81; Anthony J. Onwuegbuzie, "Writing a Research Proposal: The Role of Library Anxiety, Statistics Anxiety, and Composition Anxiety," Library and Information Science Research 19, no. 1 (1997): 5-33.

9. Anthony J. Onwuegbuzie and Qun G. Jiao, "Information Search Performance and Research Achievement: An Empirical Test of the Anxiety-Expectation Model of Library Anxiety," Jour- nal of the American Society for Information Science and Technology (JASIST) 55, no. 1 (2004): 41-54; Anthony J. Onwuegbuzie, Qun G. Jiao, and Sharon L. Bostick, Library Anxiety: Theory, Research, and Applications (Lanham, Md.: Scarecrow, 2004).

10. Diane Mizrachi, "Library Anxiety and Computer Attitudes among Israeli B.Ed. Students" (master's thesis, Bar-Ilan University, Israel, 2000); Snunith Shoham and Diane Mizrachi, "Library Anxiety among Undergraduates: A Study of Israeli B.Ed. Students," Journal of Academic Librarianship 27, no. 4 (July 2001): 305-11.

11. Ann J. Jerabek, Linda S. Meyer, and Thomas S. Kordinak, "Library Anxiety' and 'Computer Anxiety': Measures, Validity, and Research Implications," Library and Information Science Research 23, no. 3 (2001): 277-89.

12. Muhamad A. Al-Khaldi and Ibrahim M. Al-Jabri, "The Relationship of Attitudes to Computer Utilization: New Evidence from a Developing Nation," Computers in Human Behavior 9, no. 1 (Jan. 1998): 23-42; Margaret Cox, Valeria Rhodes, and Jennifer Hall, "The Use of Computer-Assisted Learning in Primary Schools: Some Factors Affecting Uptake," Computers in Education 12, no. 1 (1988), 173-78; Gayle V. Davidson and Scott D. Ritchie, "Attitudes toward Integrating Computers into the Classroom: What Parents, Teachers, and Students Report, Journal of Computing in Childhood Education 5, no. 1 (1994): 3-27; Donald G. Gardner, Richard L. Dukes, and Richard Discenza, "Computer Use, Self-Confidence, and Attitudes: A Causal Analysis," Computers in Human Behavior 9, no. 4 (winter 1993): 427-40; Robin H. Kay, "Predicting Student Teacher Commitment to the Use of Computers," Journal of Educational Computing Research 6, no. 3 (1990): 299-309.

13. Deborah Bandalos and Jeri Benson, "Testing the Factor Structure Invariance of a Computer Attitude Scale over Two Grouping Conditions," Educational and Psychological Measurement 50, no. 1 (Spring 1990): 49-60; Frank M. Bernt and Alan C. Bugbee Jr., "Factors Influencing Student Resistance to Computer Administered Testing," Journal of Research on Computing in Education 22, no. 3 (spring 1990): 265-75; Michel Dupagne and Kathy A. Krendl, "Teacher's Attitudes toward Computers: A Review of the Literature," Journal of Research on Computing in Education 24, no. 3 (Spring 1992): 420-29; Elizabeth Mowrer-Popiel, Constance Pollard, and Richard Pollard, "An Analysis of the Perceptions of Preservice Teachers toward Technology and Its Use in the Classroom," Journal of Instructional Psychology 21, no. 2 (June 1994): 131-38; Jennifer D. Shapka and Michel Ferrari, "ComputerRelated Attitudes and Actions of Teacher Candidates," Computers in Human Behavior 19, no. 3 (May 2003): 319-34.

14. Valentina McInerney, Dennis M. McInerney, and Kenneth E. Sinclair, "Student Teachers, Computer Anxiety, and Computer Experience," Journal of Educational Computing Research 11, no. 1 (1994): 27-50.

15. Susan E. Jennings and Anthony J. Onwuegbuzic, "Computer Attitudes as a Function of Age, Gender, Math Attitude, and Developmental Status," Journal of Educational Computing Research 25, no. 4 (2001): 367-84.

16. Jiao, Onwuegbuzie, and Lichtenstein, "Library Anxiety," 152.

17. Mizrachi, "Library Anxiety and Computer Attitudes"; Shoham and Mizrachi, "Library Anxiety among Undergraduates."

18. Mizrachi, "Library Anxiety and Computer Attitudes"; Shoham and Mizrachi, "Library Anxiety among Undergraduates"; 
Jerabek, Meyer, and Kordinak, “'Library Anxiety' and 'Computer Anxiety."

19. Brenda H. Loyd and Clarice Gressard, "The Effects of Sex, Age, and Computer Experience on Computer Attitudes" AEDS Journal 18 , no. 2 (1984): $67-77$.

20. Sharon L. Bostick, "The Development and Validation of the Library Anxiety Scale" (Ph.D. diss, Wayne State University, 1992).

21. Qun G. Jiao and Anthony J. Onwuegbuzie, "Reliability Generalization of the Library Anxiety Scale Scores: Initial Findings," (unpublished manuscript, 2002).

22. Onwuegbuzie, Jiao, and Bostick, Library Anxiety, 22.

23. Norman Cliff and David J. Krus, "Interpretation of Canonical Analyses: Rotated versus Unrotated Solutions," PSychometrica 41, no. 1 (Mar. 1976): 35-42; Richard B. Darlington, Sharon L. Weinberg, and Herbert J. Walberg, "Canonical Variate Analysis and Related Techniques," Review of Educational Research 42, no. 4 (fall 1973): 131-43; Bruce Thompson, "Canonical Correlation: Recent Extensions for Modeling Educational Processes" (paper presented at the annual meeting of the American Educational Research Association, Boston, Mass., Apr. 7-11, 1980) (ERIC, ED 199269); Bruce Thompson, Canonical Correlation Analysis: Uses and Interpretations (Newbury Park, Calif.: Sage, 1984); Bruce Thompson, "Canonical Correlation Analysis: An Explanation with Comments on Correct Practice" (paper presented at the annual meeting of the American Educational Research Association, New Orleans, La., Apr. 5-9, 1988) (ERIC, ED 295957); Bruce Thompson, "Variable Importance in Multiple Regression and Canonical Correlation" (paper presented at the annual meeting of the American Educational Research Association, Boston, Mass., April 16-20, 1990) (ERIC, ED 317615).

24. Margery E. Arnold, "The Relationship of Canonical Correlation Analysis to Other Parametric Methods" (paper presented at the annual meeting of the Southwest Educational Research Association, New Orleans, La., Jan. 1996) (ERIC, ED 395994).
25. Thompson, "Canonical Correlation: Recent Extensions."

26. Ibid.

27. Jacob Cohen, Statistical Power Analysis for the Behavioral Sciences (New York: Wiley, 1988).

28. Ibid.

29. Zarrel V. Lambert and Richard M. Durand, "Some Precautions in Using Canonical Analysis," Journal of Marketing Research 12, no. 4 (Nov. 1975): 468-75.

30. Anthony J. Onwuegbuzie and Larry G. Daniel, "Typology of Analytical and Interpretational Errors in Quantitative and Qualitative Educational Research," Current Issues in Education 6 , no. 2 (Feb. 2003). Accessed Nov. 13, 2003, http:/ / cie.ed.asu.edu/ volume6/number2/.

31. Barbara G. Tabachnick and Linda S. Fidell, Using Multivariate Statistics, 3rd ed. (New York: Harper), 1996.

32. Mizrachi, "Library Anxiety and Computer Attitudes"; Shoham and Mizrachi, "Library Anxiety among Undergraduates."

33. Jerabek, Meyer, and Kordinak, "Library Anxiety' and 'Computer Anxiety."

34. Qun G. Jiao, Anthony J. Onwuegbuzie, and Sharon L. Bostick, "Racial Differences in Library Anxiety among Graduate Students," Library Review 53, no. 4 (2004): 228-35.

35. Qun G. Jiao and Anthony J. Onwuegbuzie, "Library Anxiety: A Function of Race?" (unpublished manuscript, 2003).

36. Anthony J. Onwuegbuzie and Joel R. Levin, "A Proposed Three-Step Method for Assessing the Statistical and Practical Significance of Multiple Hypothesis Tests" (paper presented at the annual meeting of the American Educational Research Association, San Diego, Calif., Apr. 12-16, 2004).

37. Jiao, Onwuegbuzie, and Bostick, "Racial Differences in Library Anxiety."

38. Bostick, "The Development and Validation of the Library Anxiety Scale." 